\title{
An Observation of Cationic Influence on the $N / O$ Alkylation Selectivity in the Alkylation of a Compound Containing Several Nucleophilic Sites
}

\author{
Hans-René Bjørsvik ${ }^{\dagger, a}$, Arne Wang Aabye ${ }^{a}$, Rolf Carlson ${ }^{b}$ and Per Carlsen ${ }^{c}$ \\ ${ }^{a}$ NYCOMED Imaging AS, Department of Process Chemistry, P.O.Box 4220 Torshov, N-0401 Oslo, Norway, ${ }^{b}$ University of \\ Umeå, Department of Organic Chemistry, S-901 87 Umeå, Sweden and ${ }^{\mathrm{c}}$ The University of Trondheim, The Norwegian Institute \\ of Technology, Organic Chemistry Laboratories, N-7034 Trondheim, Norway
}

\begin{abstract}
Bjørsvik, H.-R., Aabye A. W., Carlson, R. and Carlsen, P., 1994. An Observation of Cationic Influence on the N/O Alkylation Selectivity in the Alkylation of a Compound Containing Several Nucleophilic Sites. - Acta Chem. Scand. 48: 582-588 (c) Acta Chemica Scandinavica 1994.

The reaction of $N, N^{\prime}$-bis(2,3-dihydroxypropyl)-5-acetamido-2,4,6-triiodoisophthalamide 1 with 3-chloro-1-methoxy-2-propanol 2 has been studied. In addition to the desired product $N, N^{\prime \prime}$-bis(2,3-dihydroxypropyl)-5-[ $N$-(2-hydroxy-3-methoxypropyl)acetamido]-2,4,6-triiodoisophthalamide 3, which is a pharmaceutical agent of interest as a general purpose X-ray contrast agent in medical imaging, several by-products were also formed. The by-products were formed by concomitant alkylation of other nucleophilic sites. The yield of $\mathbf{3}$ and the by-products was found to be influenced by the presence of various cations during the alkylation step. It was found that $\mathrm{Ca}^{++}$showed the most promising results, giving the highest yield of 3 as well as affording the best selectivity.

The response surface technique was used to analyze which variables influenced the desired reaction and the competing reactions. Response surface models were used to predict a detailed setting of the variables for an optimal synthetic procedure.
\end{abstract}

Nucleophilic alkylation is widely used in organic synthesis for introducing functionalized side chains into a substrate. Such reactions with oxygen-functionalized nucleophiles containing for example hydroxy, ether or poly-ether moieties are often used for the modification of pharmaceutical agents to adjust their lipophilic-hydrophilic properties in order to achieve a desirable pharmacokinetic profile. One problem which is often encountered in this context is that the substrate to be alkylated may contain several nucleophilic sites and the desired reaction is accompanied by side reactions. These by-products often cause difficult separation problems.

The problem depicted above was encountered in the last step of a multistep synthesis of the X-ray contrast agent $^{1} N, N^{\prime}$-bis(2,3-dihydroxypropyl)-5-[ $N$-(2-hydroxy-3methoxypropyl)acetamido]-2,4,6-triiodoisophthalamide 3.

The nucleophilic sites yielding the by-products are hydroxy and amino groups in the side chains. Owing to the closely neighbouring location of these groups, they may

\footnotetext{
${ }^{\dagger}$ To whom correspondence should be addressed. Present address: Euro Vanillin, PO Box 330, N-1701 Sarpsborg, Norway.
}

serve as polydentate ligands for metal ions. Chelation to such groups may therefore be used to improve the performance of the desired nucleophilic alkylation reaction. This may be achieved by introducing a suitable ion in order to block the undesired nucleophilic sites. The present paper summarizes our findings in this context.

The desired reaction is an alkylation on the acetanilide group in $N, N^{\prime}$-bis(2,3-dihydroxypropyl)-5-acetamido2,4,6-triiodoisophthalamide 1 with 3-chloro-1-methoxy-2propanol 2 as the alkylation agent. However, owing to the presence of nucleophilic sites in the side chains, this reaction yields some competing alkylation reactions to form the $O$-alkylated by-product $\mathbf{5}$ and $\mathbf{6}$ and the $\mathrm{N}$-alkylated by-product 4 , see Scheme 1.

\section{Methods and results}

Screening of metal ions. It is known that simple metal ions present sometimes intervenes in alkylation reactions. ${ }^{2-7}$ In order to determine whether the presence of metal ions in the reaction mixture might have an influence on the $O: N$ alkylation ratio, a screening experiment was run with several metal ions. The results of these experiments are summarized in Table 1. 


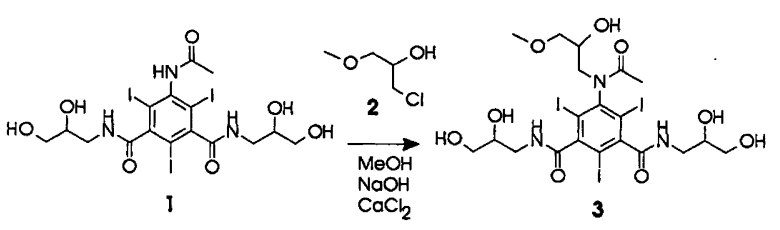<smiles></smiles>
/ 3

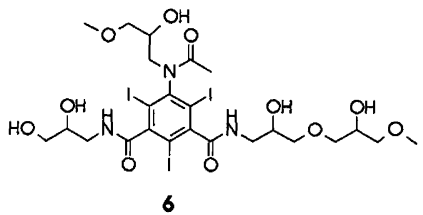

Scheme 1

Table 1. Results from HPLC measurements of the screening runs with different cations added to the reaction mixture.

\begin{tabular}{lllll}
\hline \multirow{5}{*}{$\mathrm{MCl}_{n}{ }_{n}$} & \multicolumn{3}{l}{ Response $^{a}$} & \\
\cline { 2 - 5 }$n=1,2,3$ & $y_{1}$ & $y_{2}$ & $y_{3}$ & $y_{\mathrm{r}}$ \\
\hline $\mathrm{LiCl}$ & 68.34 & 2.80 & 27.80 & 1.06 \\
$\mathrm{NaCl}$ & 60.22 & 2.36 & 36.46 & 0.96 \\
$\mathrm{KCl}$ & 59.73 & 2.32 & 36.98 & 0.97 \\
$\mathrm{CsCl}{ }^{b}$ & 48.81 & 1.71 & 48.75 & 0.73 \\
$\mathrm{MgCl}_{2} \cdot 6 \mathrm{H}_{2} \mathrm{O}^{c}$ & - & - & - & - \\
$\mathrm{CaCl}_{2}{ }^{c}$ & 87.63 & 2.40 & 9.05 & 0.92 \\
$\mathrm{SrCl}_{2} \cdot 6 \mathrm{H}_{2} \mathrm{O}$ & 89.87 & 3.07 & 6.10 & 0.96 \\
$\mathrm{BaCl}_{2} \cdot 2 \mathrm{H}_{2} \mathrm{O}$ & 78.81 & 2.17 & 17.96 & 1.06 \\
$\mathrm{CoCl}_{2}{ }^{c}$ & - & - & - & - \\
$\mathrm{ZnCl}_{2}{ }^{c}$ & - & - & - & - \\
$\mathrm{AlCl}_{3}{ }^{c}$ & - & - & - & - \\
$\mathrm{SbCl}_{3}{ }^{c}$ & - & - & - & - \\
\hline
\end{tabular}

${ }^{a} y_{1} ;$ HPLC area\% of product $3 ; y_{2}$; HPLC sum area\% of byproducts 4, 5 and $6, y_{3} ; \mathrm{HPLC}$ area\% of unchanged substrate 1, $y_{r}=100-\sum_{j=1}^{3} y_{j}{ }^{b} \mathrm{CsCl}$ were prepared from $\mathrm{Cs}_{2} \mathrm{CO}_{3}$ and conc. $\mathrm{HCl}$. ${ }^{\mathrm{C}} \mathrm{A}$ stiff precipitate was formed within $5 \mathrm{~min}$ after addition of the salt and before the addition of alkylating reagent 2.

From these experiments, it was concluded that the presence of metal ions influenced the regioselectivity of the alkylation reaction and that $\mathrm{Ca}^{++}$and $\mathrm{Sr}^{++}$showed the most promising results for blocking or decreasing the reactivity of the competing nucleophilic sites. For this reason, $\mathrm{Ca}^{++}$was selected for further studies in order to improve the procedure by optimizing the detailed experimental conditions.

Optimization study. The response surface modelling (RSM) technique was used to establish which experimen- tal conditions should be used for obtaining improved yields of the desired product with a concomitant improvement of the regioselectivity of the alkylation, i.e., suppression of by-products formation. Thorough accounts of RSM methodology have been given in the literature $^{8-10}$ and we do not here go into any details of the underlying principles.

The objectives of the present study were $(i)$ to determine which variables influence the selectivity as well as the yield of the $\mathrm{N}$-alkylation reaction; this implies that both linear and non-linear effects must be determined and (ii) to determine the optimum experimental conditions, i.e., the detailed settings of the experimental variables which yield the maximum of the desired product and minimum of side products. A yield of 3 less than $95 \%$ and a yield of 4,5 and 6 exceeding $2.5 \%$ was considered unacceptable. Quadratic response surface models were used eqn. (1).

$y=\beta_{0}+\sum_{k=1}^{K} \beta_{k} x_{k}+\sum_{k=1}^{K-1} \sum_{l=2}^{K} \beta_{k l} x_{k} x_{l}+\sum_{k=1}^{K} \beta_{k k} x_{k}^{2}+\varepsilon$

Models were determined which relate $y_{1}$, yield of the desired product 3 and the sum of the yield $\left(y_{2}\right)$ of by-products $(\mathbf{4}, 5$ and $\mathbf{6})$ to the settings of the experimental variables, $x_{k}, k=1, \ldots, 5$.

The structure of the by-products $(4,5$ and 6$)$ are very similar and it was assumed that the reactions by which they are formed would depend in a similar way on variations in experimental conditions. For this reason, the sum of the yields of by-products was used as single measure of the undesired reactions. ${ }^{+}$

Experimental variables as well as the explored range of their variation are specified in Table 2 . A brief discussion of why these variables were selected follows.

Amount of alkylating agent, $\mathrm{x}_{1}$. It would be beneficial from a practical and economical point of view if a stoichiometric amount of $\mathbf{2}$ could be used. However, initial experiments had shown that an excess should be used for obtaining a reasonably high yield. The question was therefore, how large an excess should be used.

Amount of sodium hydroxide, $\mathrm{x}_{2}$. The product 3 is baselabile and the basicity of the reaction mixture might influence the rate of hydrolytic degradation of 3 . For this reason, the amount of sodium hydroxide in the reaction

\footnotetext{
${ }^{\dagger}$ The experimental error of each of the observed yields can safely be assumed to be approximately normal and independently distributed, $N I D\left(0, \sigma^{2}\right)$. For this reason, $y_{2}$ which is the observed sum of the by-product yields will also have a normal distributed error. The significance of the experimental variables are evaluated from cumulative normal probability distribution plots and for such analysis a normal distributed error is essential. It is, however, common to use ratios of observed yields as a measures of selectivity. Such ratios will not have a normal distributed error.
} 
Table 2. Experimental design and results from HPLC analysis

\begin{tabular}{|c|c|c|c|c|c|c|c|c|}
\hline \multirow[b]{2}{*}{ \# } & \multicolumn{5}{|c|}{ Experimental variable ${ }^{a}$} & \multicolumn{3}{|c|}{ Response $^{b}$} \\
\hline & $x_{1}$ & $x_{2}$ & $x_{3}$ & $x_{4}$ & $x_{5}$ & $y_{1}$ & $y_{2}$ & $y_{3}$ \\
\hline 1 & -1 & -1 & -1 & -1 & +1 & 81.255 & 1.393 & 15.864 \\
\hline 2 & +1 & -1 & -1 & -1 & -1 & 90.823 & 3.494 & 4.059 \\
\hline 3 & -1 & +1 & -1 & -1 & -1 & 89.293 & 2.239 & 7.372 \\
\hline 4 & +1 & +1 & -1 & -1 & +1 & 94.076 & 3.615 & 0.913 \\
\hline 5 & -1 & -1 & +1 & -1 & -1 & 87.900 & 2.420 & 8.560 \\
\hline 6 & +1 & -1 & +1 & -1 & +1 & 93.867 & 3.213 & 1.580 \\
\hline 7 & -1 & +1 & +1 & -1 & +1 & 90.852 & 2.212 & 5.720 \\
\hline 8 & +1 & +1 & +1 & -1 & -1 & 93.376 & 4.411 & 1.072 \\
\hline 9 & -1 & -1 & -1 & +1 & -1 & 66.234 & 1.581 & 29.970 \\
\hline 10 & +1 & -1 & -1 & +1 & +1 & 83.852 & 2.019 & 12.613 \\
\hline 11 & -1 & +1 & -1 & +1 & +1 & 85.790 & 1.430 & 12.130 \\
\hline 12 & +1 & +1 & -1 & +1 & -1 & 89.970 & 2.300 & 6.970 \\
\hline 13 & -1 & -1 & +1 & +1 & +1 & 58.008 & 1.285 & 38.366 \\
\hline 14 & +1 & -1 & +1 & +1 & -1 & 89.840 & 4.058 & 3.302 \\
\hline 15 & -1 & +1 & +1 & +1 & -1 & 88.520 & 2.225 & 8.120 \\
\hline 16 & +1 & +1 & +1 & +1 & +1 & 93.627 & 3.409 & 1.472 \\
\hline 17 & -2 & 0 & 0 & 0 & 0 & 73.430 & 1.120 & 24.310 \\
\hline 18 & +2 & 0 & 0 & 0 & 0 & 91.112 & 3.270 & 3.557 \\
\hline 19 & 0 & -2 & 0 & 0 & 0 & 59.215 & 1.256 & 36.861 \\
\hline 20 & 0 & +2 & 0 & 0 & 0 & 92.650 & 2.590 & 2.930 \\
\hline 21 & 0 & 0 & -2 & 0 & 0 & 79.800 & 0.960 & 18.400 \\
\hline 22 & 0 & 0 & +2 & 0 & 0 & 94.003 & 3.360 & 1.700 \\
\hline 23 & 0 & 0 & 0 & -2 & 0 & 91.203 & 2.528 & 4.234 \\
\hline 24 & 0 & 0 & 0 & +2 & 0 & 83.103 & 1.389 & 12.578 \\
\hline 25 & 0 & 0 & 0 & 0 & -2 & 89.950 & 2.727 & 5.647 \\
\hline 26 & 0 & 0 & 0 & 0 & +2 & 86.070 & 1.590 & 10.670 \\
\hline 27 & 0 & 0 & 0 & 0 & 0 & 88.739 & 2.427 & 6.823 \\
\hline 28 & 0 & 0 & 0 & 0 & 0 & 89.794 & 2.666 & 6.039 \\
\hline 29 & 0 & 0 & 0 & 0 & 0 & 90.411 & 2.488 & 5.892 \\
\hline 30 & 0 & 0 & 0 & 0 & 0 & 88.765 & 3.478 & 5.015 \\
\hline 31 & 0 & 0 & 0 & 0 & 0 & 90.189 & 3.012 & 4.688 \\
\hline 32 & 0 & 0 & 0 & 0 & 0 & 90.753 & 2.701 & 4.678 \\
\hline
\end{tabular}

${ }^{a}$ Experimental variables: $x_{k}$ (Definition) [levels: $\left.-1,0,+1\right]$ : $x_{1}$; (amount of $\mathrm{NaOH}$ /equiv.) [1.30, 1.45, 1.60]; $x_{2} ;$ (amount of $\mathrm{CaCl}_{2}$ /equiv.) $[0.80,1.15,1.50] ; x_{3},\left(T /{ }^{\circ} \mathrm{C}\right)[25.0,32.5,40.0] ; x_{4} ;$ (substrate concentration $/ \mathrm{g} \mathrm{ml}^{-1}$ ) $[1.00,1.35,1.70] ;$ $x_{5}$; (amount of 3-chloro-1-methoxy-2-propanol/equiv.) $[1.40,1.55,1.70] .{ }^{b} y_{1} ;$ HPLC area\% of product $3 ; y_{2} ;$ HPLC sum area\% of by-products 4,5 and $6 ; y_{3} ;$ HPLC area\% of unchanged substrate 1 .

mixture should be kept to a minimum. However, a certain amount is necessary to obtain a homogeneous mixture, but in preliminary experiments it was observed that too high a $\mathrm{pH}$ promoted the formation of by-products.

Amount of calcium chloride, $\mathrm{x}_{3}$. It was observed that cations, added as chlorides to the reaction mixture, influenced the rate and the selectivity. The effects of the cation were assumed to be due to formation of a chelate complex with the adjacent free hydroxy groups in the substrate $\mathbf{1}$, or to coordination between the acetanilide anion, the cation and the alkylating agent $\mathbf{2}$. The properties of the complex are likely to be dependent on the ionic surface area of the substrate and the charge of the cation. It was found that $\mathrm{Ca}^{++}$and $\mathrm{Sr}^{++}$showed the 'best' properties both with respect to the decrease in the formation of the by-products $(4,5$ and 6$)$, and an increase in the reaction rate as well as an improved yield of $\mathbf{3}$. For economic reasons, $\mathrm{Ca}^{++}$was selected for further studies. The concentration of $\mathrm{Ca}^{++}$in the reaction mixture may be critical, but from a practical and industrial point of view an amount as small as possible was desired. The question is therefore, how much is necessary to achieve the goal.

Substrate concentration, $\mathrm{x}_{4}$. For preparative runs, a high substrate concentration is desirable. However, too high a substrate concentration increases the viscosity of the reaction mixture. This may lead to concentration gradients during the addition of the alkylation agent, which may, in turn, have a detrimental effect on the selectivity of the reaction. For this reason, the concentration of the substrate must be considered.

Reaction temperature, $\mathrm{x}_{5}$. The selectivity depends on the relative rates of the desired and side reactions and since the specific rates of these reactions may have different temperature dependences, variation of the reaction temperature was explored.

Reaction time. The reaction time, defined as the run time before quenching the reaction mixture, was not included 
as a design variable. Initially experiments in which the course of the reaction was monitored up to a total reaction time of $48 \mathrm{~h}$ showed that the pattern of product distribution did not change, compared with what was observed after $24 \mathrm{~h}$. For evaluation of the optimum conditions, the total reaction time of $24 \mathrm{~h}$ was fixed.

Experimental design and response surface model. A central composited rotable design ${ }^{10}$ was used. The design matrix and yields obtained in the experimental runs are summarized in Table 2. From the data in Table 2, the response surface model parameters $(\beta)$ were computed using the PLSR method. ${ }^{11}$ The significance of the parameters were estimated from the cumulative normal probability plots shown in Fig. 1. From these plots the following conclusions were drawn as to the influence of the experimental variables (significant variables accounted).

Model for 3. Main effect(s): $\beta_{1}$ (amount of sodium hydroxide), $\beta_{2}$ (amount of calcium chloride), $\beta_{4}$ (substrate concentration). Interaction effect(s): $\beta_{12}$ (amount of sodium hydroxide $\times$ amount of calcium chloride), $\beta_{14}$ (amount of sodium hydroxide $\times$ substrate concentration), $\beta_{24}$ (amount of calcium chloride $\times$ substrate concentration), and $\beta_{35}$ (reaction temperature $\times$ amount of alkylation agent). Quadratic effect(s): $\beta_{22}$ (square of amount of calcium chloride).

(a)

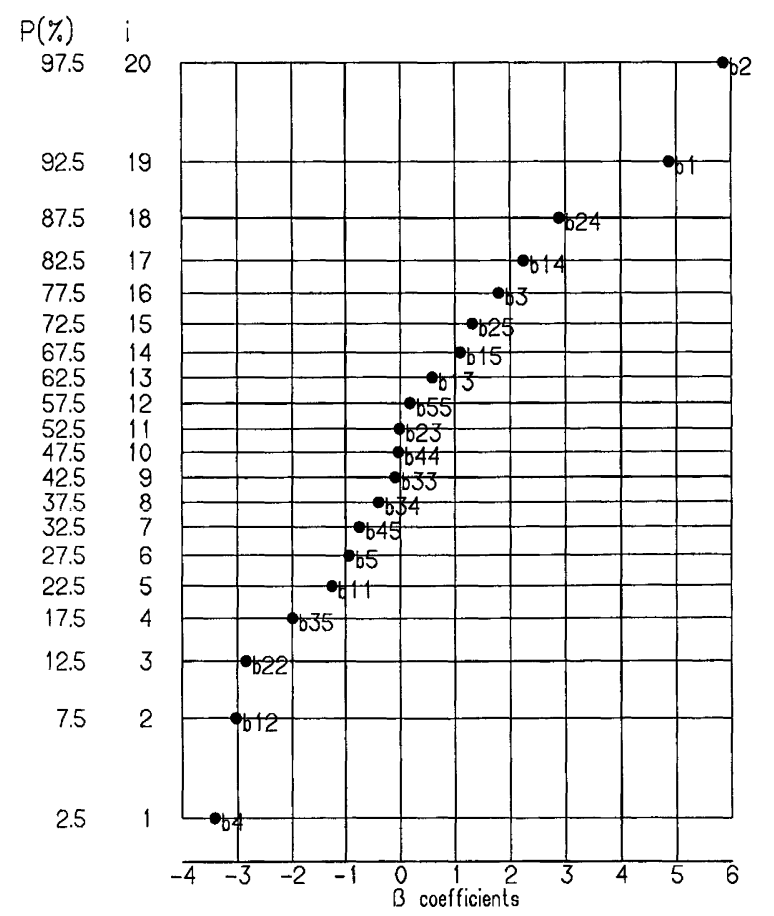

Model for 4, 5 and 6. Main effect(s): $\beta_{1}$ (amount of sodium hydroxide), $\beta_{3}$ (reaction temperature), and $\beta_{4}$ (substrate concentration). Interaction effect(s): $\beta_{25}$ (amount of calcium chloride $\times$ amount of alkylation agent). Quadratic effect(s): none. After removal of insignificant terms, the following estimated models were obtained for $3\left(y_{1}\right)$ and 4, 5 and $6\left(y_{2}\right)$ respectively, eqns. (2) and (3).

$$
\begin{aligned}
y_{1} & =88.21+4.87 x_{1}+5.86 x_{2}-3.41 x_{4} \\
& =-3.02 x_{1} x_{2}+2.89 x_{2} x_{4}-2.00 x_{3} x_{5}-2.754 x_{2}^{2} \\
y_{2} & =2.40+0.75 x_{1}+0.50 x_{3}-0.21 x_{4}+0.32 x_{2} x_{5}
\end{aligned}
$$

Plots of residuals versus estimated response, and normal probability plots of the residuals showed acceptable features. ${ }^{12,13}$ Isocontour projections of the response surfaces are shown in Fig. 2. These projections show that the optimum result was to be expected under the following conditions.

The substrate $1(200 \mathrm{~g}, 0.268 \mathrm{~mol})$ was dissolved in a solution of sodium hydroxide $(18.2 \mathrm{~g}, 0.455 \mathrm{~mol}$, 1.7 equiv. $)$ in methanol $(220 \mathrm{ml})\left(1.10 \mathrm{ml} \mathrm{g}^{-1}\right)$. When the substrate was completely dissolved, the reaction temperature was adjusted to $10^{\circ} \mathrm{C}$. Calcium chloride $(41.5 \mathrm{~g}$, 0.374 mol, 1.4 equiv.) was added and the reaction mixture was stirred for $15 \mathrm{~min}$ and the alkylation agent 2 $(56.5 \mathrm{~g}, 0.454,1.60$ equiv.) was added in one portion. Samples from the reaction mixture were withdrawn after $t=24 \mathrm{~h}, 48 \mathrm{~h}$, and $72 \mathrm{~h}$ and the composition of the mixture was determined by HPLC.

(b)

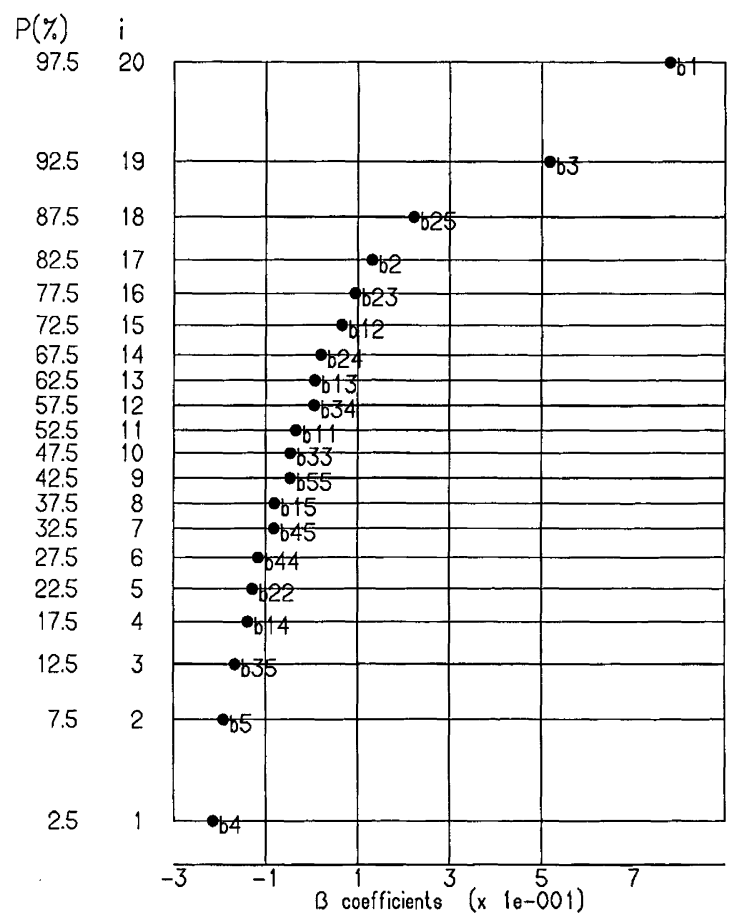

Fig. 1. Normal probability plot of the estimated regression coefficients: (a) model for desired product $3 ;(b)$ model for the sum of by-products 4,5 and 6. 
(a)

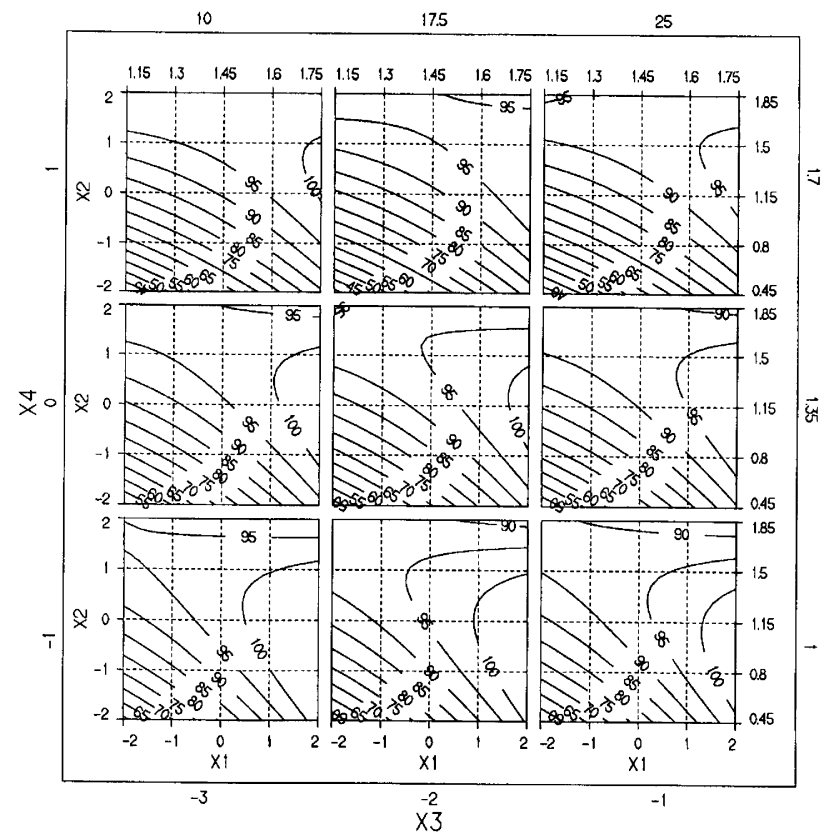

(b)

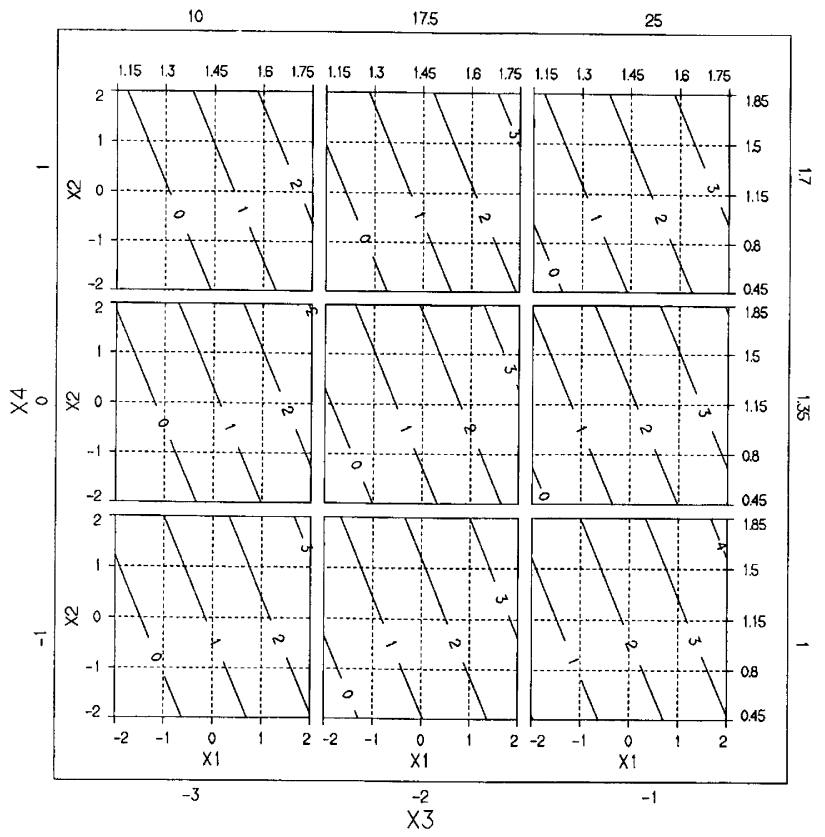

Fig. 2. Contour plots of the response surfaces showing the yield of (a) $\mathbf{3}$ and (b) sum of $\mathbf{4}$, $\mathbf{5}$ and $\mathbf{6}$. The plots show the variations of the responses when the four experimental variables $x_{1}$ (amount of $\mathrm{NaOH} /\left[\right.$ equiv.]); $x_{2}$, (amount of $\mathrm{CaCl}{ }_{2} /[$ equiv.]), $x_{3},\left(T /{ }^{\circ} \mathrm{C}\right.$ ), and $x_{4}$, (substrate concentration $/ \mathrm{g} \mathrm{ml}^{-1}$ ) are varied, and one variable is fixed, $x_{5}=+1(1.70$ equiv. of $3-\mathrm{chloro}-$ 1-methoxy-2-propanol). To read the plot, the large frame shows the variation in reaction temperature ( $\left.x_{3}\right)$ and substrate concentration $\left(x_{4}\right)$. In this frame, nine subplots showing the contour projections of the surface when the amount of calcium chloride $\left(x_{2}\right)$ and the amount of sodium hydroxide $\left(x_{1}\right)$ are varied. For instance, the variation in response for the settings $x_{3}=-1$, $x_{4}=-1$ and the varying of $x_{2}$ and $x_{1}$ is shown in the subplot in the lower left-hand corner of the figure. Other settings are evaluated analogously.

Experiments conducted under these conditions afforded for $t=24 \mathrm{~h}$ an $83.85 \%$ yield of 3 and $1.06 \%$ of $\mathbf{4}$, 5 and 6; for $t=48 \mathrm{~h} 96.08 \%$ yield of 3 and $2.06 \%$ of $\mathbf{4}$, 5 and 6; and for $t=72 \mathrm{~h}$ a $96.80 \%$ yield of 3 and $2.31 \%$ of 4,5 and 6 and these results confirmed the conclusions.

\section{Discussion and conclusion}

The results obtained verify our assumption that an increased $N: O$ ratio could be obtained by adding $\mathrm{Ca}^{++}$ions to the reaction mixture. It was also observed that the rate of the product-forming reaction was considerably increased. This result cannot be explained by a blocking of the competing nucleophilic sites of the substrate. Some other effects must also intervene.

The results of semiempirical molecular orbital calculations ${ }^{14,15}$ of the partial charges on the nucleophilic sites of the substrate without complexing cations and with singly charged, and doubly charged cations present is shown in Table 3.

It is seen that the charge of the desired nucleophilic site is increased in the presence of cations. This may explain the increased rate and may contribute to the improved selectivity. Another factor which may contribute to the improved selectivity is that the agent can form an epoxide in situ under the basic conditions used. The epoxide thus formed may be coordinated to $\mathrm{Ca}^{++}$ions which assist in the ring opening alkylation reaction.

The response surface model shows that it is, however, necessary to use almost stoichiometric amounts of the $\mathrm{Ca}^{++}$ions. These results, indicated that trivalent ions should also be evaluated in order to increase the partial charge on the desired nucleophilic site. However, a test run with $\mathrm{AlCl}_{3}$ added to the reaction mixture did not afford the desired improvement of the alkylation reaction.

Table 3. Calculated partial charge distribution on nucleophilic sites in the substrate 1.

\begin{tabular}{lllll}
\hline & \multicolumn{4}{l}{ Partial charge in substrate } \\
\cline { 2 - 5 } Functional & $\begin{array}{l}\text { Neutral } \\
\text { group }\end{array}$ & \multicolumn{4}{l}{ Anion with counter ion } \\
\cline { 2 - 5 } & molecule & None & $\mathrm{M}^{+}$ & $\mathrm{M}^{++}$ \\
\hline Ar-[N] & -0.380 & -0.404 & -0.559 & -0.718 \\
$\mathrm{ArN}-\mathrm{C}[\mathrm{O}]$ & -0.341 & -0.402 & -0.516 & -0.602 \\
$\mathrm{ArCO}-[\mathrm{N}] \mathrm{H}$ & -0.253 & -0.379 & -0.258 & -0.349 \\
$\mathrm{ArC}[\mathrm{O}]-\mathrm{NH}$ & -0.325 & -0.350 & -0.333 & -0.309 \\
sec-[O]H & -0.341 & -0.351 & -0.340 & -0.342 \\
prim-[O]H & -0.326 & -0.337 & -0.330 & -0.324 \\
\hline
\end{tabular}

a The partial charge is given for the atom given in brackets [ ]. 
Such highly charged ions will be strongly solvated in methanol (the solvent used) and therefore less prone to coordinate to the substrate or the reagent.

Since only one reaction has been studied, it is not possible to draw any general conclusions as to increased reactivity in the presence of complexing cations of polyfunctional nucleophiles. The results are, however, promising and motivate further studies.

\section{Experimental}

Chemicals. The substrate 1 was obtained from Nycomed, the agent $\mathbf{2}$ was supplied by Borregaard Fine Chemicals, other chemicals and solvents were obtained from EKA Nobel (sodium hydroxide), Merck [hydrochloric acid, methanol, antimony(III) chloride, lithium chloride, potassium chloride, cesium carbonate, cobolt chloride], Norsk Medisinaldepot (sodium chloride, aluminium chloride), and Fluka (magnesium chloride hexahydrate, strontium chloride hexahydrate, barium chloride dihydrate, zinc chloride). The quality was p.a. or 'for synthesis'.

General procedure for the screening experiment for the cations. The substrate $1(100 \mathrm{~g}, 0.134 \mathrm{~mol})$ was dissolved in a solution of sodium hydroxide $(7.5 \mathrm{~g}, 0.187 \mathrm{~mol}$, 1.4 equiv.) in methanol $(150 \mathrm{ml})$. When the substrate 1 was completely dissolved, the reaction temperature was adjusted to $30^{\circ} \mathrm{C}$, and the metal chloride (1.0 equiv., $0.134 \mathrm{~mol}$ ) was added (where $\mathrm{M}=\mathrm{Li}, \mathrm{Na}, \mathrm{K}, \mathrm{Cs}, \mathrm{Mg}, \mathrm{Ca}$, $\mathrm{Sr}, \mathrm{Ba}, \mathrm{Co}, \mathrm{Zn}, \mathrm{Al}$ and $\mathrm{Sb}$ ). The reaction mixture was stirred for $15 \mathrm{~min}$, then the alkylation agent 2 (20.7 g, 0.187 mol, 1.4 equiv.) was added in one portion. Samples from the reaction mixture were withdrawn after $24 \mathrm{~h}$ and the composition of the mixture was determined by HPLC. The results obtained are summarized in Table 1.

General procedure for the response surface experiment. Settings of the variables, $x_{1}-x_{5}$, in the individual runs and the results obtained are summarized in Table 2 .

$N, N^{\prime}$-Bis(2,3-dihydroxypropyl)-5-acetamido-2,4,6-triiodoisophthalamide $1(200 \mathrm{~g}, 0.268 \mathrm{~mol})$ was dissolved in a solution of sodium of sodium hydroxide $\left(x_{2} \mathrm{~g}\right)$ in methanol $\left(x_{5} \mathrm{ml}\right)$.

When the substrate 1 was completely dissolved, the given amount $\left(x_{3}\right)$ of calcium chloride was added and the reaction mixture was stirred for $15 \mathrm{~min}$. The amount $\left(x_{1}\right)$ of the alkylation agent $\mathbf{2}$ was added in one portion. Samples from the reaction mixture were withdrawn after $24 \mathrm{~h}$ and the composition of the mixture was determined by HPLC.

HPLC analysis. The reaction mixture was analysed by HPLC to determine the amounts of product, by-products and unchanged substrate. The integrated peak areas were used for quantification.

Two eluents, A and B, were used. Eluent A was pure acetonitrile and eluent $B$ was purified water. The eluents were degassed with helium prior to use.
The solvent delivery system used was gradient pumping $3-17 \%$ of eluent $\mathrm{A}$, for $60 \mathrm{~min}$ with a flow rate of $1.0 \mathrm{ml} \mathrm{min}{ }^{-1}$. The columns used were RP-18, Brownlee Columns (L $250 \mathrm{~mm}$, ID $4.6 \mathrm{~mm}$ ) and particle size $5 \mu \mathrm{m}$. A UV detector operating at wavelength $\lambda=254 \mathrm{~nm}$ was used.

Computing. In-house developed software SynDe (Synthesis Design) written in Zortech $\mathrm{C} / \mathrm{C}++$ version 3.0 was used for creating the experimental design, for plotting the cumulative normal probability graphs, and for calculating and plotting the response surfaces.

The UNSCRAMBLER program version $5.00^{16}$ was used to estimate the regression coefficients, by means of the partial least-squares regression (PLSR) method, ${ }^{11}$ with the cross-validation method $^{17}$ for validation purposes. All the computation was performed under DOS 5.0 on a COMPAQ DESKPRO 50M, a 32 bit $i 486$ microprocessor-based microcomputer.

Molecular mechanics calculations. The calculation of the atomic point charge for the anion of the substrate 1 was done by use of the AM1 (Austin Model 1) $14,18,19$ method.

The AM1 routine used in the present work was the one routine implemented in the semiempirical quantum chemistry software MOPAC $6.0^{15,20}$ with key words: AM1 PRECISE GNORM $=0.2 \mathrm{MMOK}$. The MOPAC program was run on a VAX computer under VMS.

Acknowledgements. The Department of Chemical Analysis at Nycomed Imaging AS is acknowledged for excellent technical assistance concerning the HPLC analysis. Nycomed Imaging AS is acknowledged for the kind permission to publish this paper. Financial support from the Swedish Natural Science Research Council (RC) is gratefully acknowledged.

\section{References}

1. Sovak, M. In: Sovak, M., Ed., Radiocontrast Agents, Springer-Verlag, Berlin, 1984, Introduction; Hoey, G. B. and Smith, K. R. In: Sovak, M., Ed., Radiocontrast Agents, Springer-Verlag, Berlin, 1984, Chap. 1.

2. Loupy, A. and Tchoubar, B. Salt Effects in Organic and Organometallic Chemistry, VCH, Weinheim, 1992, pp. 134-135.

3. Smith, P. A. S. and Robertson, J. E. J. Am. Chem. Soc. 84 (1962) 1197.

4. Smith, S. G. and Milligan, D. V. J. Am. Chem. Soc. 90 (1968) 2393.

5. Smith, S. G. and Hanson, M. P. J. Org. Chem. 36 (1971) 1931.

6. LeNoble, W. J. and Palit, S. K. Tetrahedron Lett. (1972) 493.

7. Carlsen, P. and Aabye, W. A. Research Report, Norwegian Institute of Technology (NTH) 1988.

8. Box, G. E. P. and Hunter, J. S. Ann. Math. Statist. 28 (1957) 195.

9. Box, G. E. P. and Hunter, J. S. In: Chew, V., Ed., Experimental Designs in Industry, Wiley, New York, 1958, pp. 138190.

10. Box, G. E. P. and Draper, N. R. Empirical Model-Building 
and Response Surfaces, Wiley, New York, 1987, pp. 305312, 440-441.

11. Martens, H. and Næs, T. Multivariate Calibration, Wiley, New York 1991, pp. 116-165.

12. Draper, N. R. and Smith, H. Applied Regression Analysis, 2nd ed., Wiley, New York, 1981, pp. 147-148.

13. Daniel, C. Technometrics 1 (1959) 311.

14. Stewart, J. J. P. Journal of Computer-Aided Molecular Design 4 (1990) 1.

15. Clark, T. A Handbook of Computational Chemistry, A Practical Guide to Chemical Structure and Energy Calculations, Wiley, New York, 1985.
16. UNSCRAMBLER, V5.0 Standard and Extended memory version. User's Guide 1992. CAMO A/S, Olav Trygvassons gate 24, N-7011 Trondheim, Norway.

17. Wold, S. Technometrics 20 (1978) 397.

18. Dewar, M. J. S., Zoebisch, E. G., Healy, E. F. and Stewart, J. J. P. J. Am. Chem. Soc. 107 (1985) 3902

19. Dewar, M. J. S. and Dieter, K. M. J. Am. Chem. Soc. 108 (1986) 8075.

20. Stewart, J. J. P. MOPAC 93.00 Manual, Fujitsu Limited, Tokyo, 1993.

Received January 7, 1994. 